\title{
O CLUBE DA LUTA DE DAVID FINCHER À LUZ DO PSIQUISMO FREUDIANO
}

\author{
doi> 10.33726/akdpapers2447-7656v10a62020p70-83 \\ PESSOA, Marcelo ${ }^{1}$ - id https://orcid.org/0000-0002-9193-4604
}

RESUMO: Neste texto, investigamos o modo como o filme Fight Club (Clube da Luta, de David Fincher, 1999), realizou uma apropriação de alguns pontos da teoria psicanalítica freudiana, traçando paralelos que explicassem a sensação de desconforto que o homem moderno sente face à frustração provocada pelo apelo consumista. Originalmente este estudo foi publicado em formato impresso, na Revista UNORP (vol. 7, p. 117-129, ano de 2004), sob o título O Filme Clube da Luta: um Paradoxo Triádico à Luz do Pensamento de Freud. Desde então, a obra fílmica analisada se tornou extremamente estudada por outros pesquisadores e revisitada pelos diversos veículos midiáticos tradicionais e de streaming. Em 2020, em função da pandemia de COVID-19, criou-se a necessidade de fortalecer os repositórios digitais da Universidade de Estado de Minas Gerais, Unidade Frutal, com estudos de impacto sobre conteúdos imagéticos, permitindo-se, assim, melhores condições de acesso aos discentes aos materiais didáticos das aulas remotas durante o isolamento social. Desse modo, adequamos a escrita aos postulados da nova ortografia que passou a viger a partir de 2011, bem como, na medida do possível, revisamos e atualizamos alguns itens da discussão no paper. Vale lembrar, enfim, que em nosso texto havia e ainda há pontos de contato com as obras Totem $e$ Tabu (1913/14), O Ego e o ld (1969), e O Mal-Estar na Civilização (2002). Como resultados à primeira publicação esperados e ainda possíveis nesta reedição, sugerimos um cotejamento destes conteúdos com aqueles que envolvem a linguagem verbal, a imagem em movimento e a linguagem teórica da psicanálise, acentuando-se o caráter cognitivo e teórico de aproximação entre tais premissas e os ditames da semiótica cultural.

PALAVRAS-CHAVE: Clube da Luta, Semiótica Cultural, Freud, COVID-19

ABSTRACT: In this text, we investigate how the film Fight Club (The Fight Club, by David Fincher, 1999), appropriated some points of Freudian psychoanalytic theory, drawing parallels that explain the feeling of discomfort that modern man feels in the face of frustration caused by the consumerist appeal. Originally this study was published in printed format, in the UNORP Journal (vol. 7, p. 117-129, year 2004), under the title The Fight Club Movie: a Triadic Paradox in the Light of Freud's Thought. Since then, the film work analyzed has become extremely studied by other researchers and revisited by the various traditional media and streaming media. In 2020, due to the COVID-19 pandemic, there was a need to strengthen the digital repositories of the State University of Minas Gerais, Frutal Unit, with impact studies on imagery content, thus allowing better conditions for access to students to the teaching materials of remote classes during social isolation. In this way, we adapted the writing to the postulates of the new spelling that became effective in 2011 , as well as, as far as possible, revised and updated some items of the discussion in the paper. Finally, it is worth remembering that in our text there were and still are points of contact with the works Totem and Tabu (1913/14), The Ego and the Id (1969), and The Malaise in Civilization (2002). As results to the first publication expected and still possible in this reissue, we suggest a comparison of these contents with those involving the verbal language, the moving image and the theoretical language of psychoanalysis, emphasizing the cognitive and theoretical character of approximation between such premises and the dictates of cultural semiotics.

KEYWORDS: Fight Club, Cultural Semiotics, Freud, COVID-19

${ }^{1}$ Doutor em Letras pela Universidade Estadual de Londrina. Orientador e Docente na UEMG - Unidade Frutal. Departamento de Linguística, Letras, Comunicação e Artes - DLLCA. 


\section{INTRODUÇÃO}

Há pelo menos 20 anos ministrando disciplinas de Comunicação Comparada, Semiótica da Imagem e afins nos cursos superiores da área de Comunicação Social, tive a oportunidade de desenvolver uma relação praticamente anímica com diversas manifestações da linguagem pictórica, principalmente com as empregadas nas imagens fixas ou em movimento durante as comunicações de entretenimento, publicitárias ou jornalísticas.

A peculiaridade sintética e informativa do texto (verbal ou imagético) informativo, publicitário ou oriundos da indústria cultural não se nos apresentou como obstáculo para as intervenções críticas mais abstratas durante as aulas. Com esse contato sui generis, a interface aprendizado/conteúdo se desenvolveu pautada pela síntese, precisão e coerência científica, que, embora condicionantes, não limitaram e ainda não limitam a fluência do processo de ensino, quer sejam consideradas sob o aspecto das aulas presenciais físicas, quer sejam vistas sob o prisma dos ambientes remotos de produção e difusão do conhecimento, posto que tão-somente os diversos contextos socioculturais de dispersão destas informações contribuíram com elementos diferentes para enriquecer a relação e não para obstruir.

Portanto, no intuito de demonstrar nuances de uma experiência didática relacionada a elementos intertextuais e ao trânsito semiótico durante a prática docente nos cursos superiores, é que nos propusemos, por intermédio de uma breve análise do filme Clube da Luta (Fight Club), de David Fincher (1999), traçar um paralelo entre postulados da Semiótica Cultural com algumas das postulações teórico-psicanalíticas de Sigmund Freud.

Para esse efeito, fizemos alusão, no paper, a pelo três dos principais momentos ideológicos presentes no filme (o terrorismo, a felicidade, a civilização), buscando, sempre, realizar a conexão semântica provável desses momentos ideológicos idealizados na linguagem da imagem móvel, oferecendo ao leitor um material de pesquisa subsidiário a todas as áreas do conhecimento que se correlacionem aqui. 


\section{O TERRORISMO}

Como primeiro viés de investigação, é praticamente inevitável estabelecermos a conexão entre os fatos ocorridos em 2001, nos EUA, e os eventos ficcionais roteirizados por David Fincher. Assim, é interessante de se notar a trágica coincidência que se seguiu aos atos preparatórios terroristas impetrados pelos personagens do filme (estreado em 1999), com o atentado terrorista lançado às torres gêmeas do complexo financeiro do World Trade Center, nos Estados Unidos, em 11 de setembro de 2001.

Numa espécie de premonição macabra, David Fincher (1999), na cena final de seu polêmico filme Clube da Luta, destrói por decepação simbólica o coração financeiro e símbolo ereto do imperialismo norte-americano, com as bombas presas aos pilares subterrâneos dos edifícios do complexo World Trade Center. Durante o filme, os personagens, ao institucionalizarem o Clube da Luta como território de resistência ao capitalismo mundial, intencionam destruir as principais torres do World Trade Center com artefatos explosicos (na vida real, dois anos depois, isso de fato ocorreu, com os aviões projetados nos prédios, supostamente lançados ali pelos terroristas da Al Qaeda (organização fundamentalista islâmica, de alcance internacional, fundada em Agosto de 1988, por Osama bin Laden).

Como efeito colateral perverso do ataque da Al Qaede aos EUA, parece que, depois de 2001, se alastrou pelo mundo inteiro uma sensação de fracasso existencial com relação aos rumos de nossa civilização, acompanhado de uma alta comoção humanitária e sociocultural, e de certo desespero, desconforto e desilusão existencial coletiva, mais ou menos como o que temos vivenciado no mundo, desde que a pandemia de COVID-19 se instalou como fato concreto no Planeta (em meados de fevereiro de 2020).

Quanto ao nosso relato fílmico de 1999 e ao seu correlato objetivo de 2001, são argumentos próprios da semiótica cultural, considerarmos que, ao que nos parece, a humanidade sentiu certa necessidade de regredir a um estágio mental infantil e, infantilmente fragilizada pela autocomiseração trágica, 
a sociedade internacional prostrou-se passivamente ao jugo do látego do grande pai arquetípico, que detém a legitimidade do direito de punir.

No entanto, certa parcela da "criança humanidade", a julgar pelos resultados societários que tem produzido, não sabe ou não dimensiona com consciência plausível que fez uma travessura muito grave, e não entende direito porque o grande pai arquetípico ordena que ela se cale imediatamente, e que também a esteja repreendendo, e que lhe mande engolir o choro. Esse engolir o choro traz consigo o efeito colateral do recalque e prenuncia uma atmosfera de consequências severas para a expectativa de sobrevivência sociológica da humanidade.

Comenta Freud, em sua obra Totem e Tabu (1913/14, p. 225), que a supressão forçada dos instintos mais fortes do homem, por meios externos a ele, não são capazes de produzir, principalmente numa criança, o efeito de aniquilamento desses instintos. A premissa, nesse caso, é a de que a pretensa ilusão do controle dos impulsos através da repressão pode, em última análise, conduzir o indivíduo à imprevisibilidade de uma ruína emocional repentina e sem precedentes históricos, potencializada. Noutros termos:

A sublimação do instinto constitui um aspecto particularmente
evidente do desenvolvimento cultural [... assim], é impossível
desprezar até que ponto a civilização é construída sobre a
renúncia ao instinto, o quanto ela pressupõe a não-satisfação [...]
de instintos poderosos. Essa frustração cultural [...], como já
sabemos, é a causa da hostilidade contra a qual todas as
civilizações têm de lutar (FREUD, 2002, p. 52).

Esses efeitos foram deveras dimensionados e trabalhados pela máquina de propaganda governamental norte-americana por décadas. Portanto, se eles realmente quisessem, até sem muito esforço conseguiriam ratear a reconstrução das torres destruídas com doações internacionais. Não necessariamente dos governos dos Estados-nação, mas do povo mesmo, pois o homem comum se solidariza, em meio às catástrofes, com a dor do outro homem, o que explica em muitos níveis o sucesso das vaquinhas virtuais e o imenso volume de doações quando se noticiam terremotos, tsunamis, furacões. Aparentemente eles, os EUA, não o quiseram, pelo menos não de forma direta e imediata. 
É inegável, entretanto, que o Estado-nação norte-americano fez um aproveitamento político e ideológico desse terrível episódio, senão de outro modo, como instrumento arrecadatório, o fez, ao menos, ao gosto da semiótica cultural, isto é, como instrumento de manipulação de consciências - em nível liminar e subliminar.

A afetação do prócer daquela nação acabou (George W. Bush, presidente dos EUA entre 2001 e 2009), sob o pretexto argumentativo de um necessário e urgente combate a futuros atentados terroristas, por conduzir seu próprio povo (e também uma boa parte do mundo) a lançarem-se numa guerra bélica e ideológica contra vários países do Oriente Médio.

Além disso, Bush os convenceu, também, a embrenharem-se numa busca desenfreada por um apátrida utópico qualquer que lhes servisse de bode expiatório - convenientemente encarnados nas pessoas de Osama Bin Laden ou Sadam Russein, Abu Bakr al-Baghdadi (líder dos fundamentalistas do Estado Islâmico, morto em 2019) ou outros quaisquer. Convém notar a esse respeito que, a julgar-se pela sanha de caçada a esses personagens do mal, que os EUA não hesitariam em apontar para qualquer um de nós como seus alvos.

Assim, não é inoportuno afirmar que, no filme de Fincher, ao instituir-se o consumismo como alvo simbólico, em certa medida, as balas perdidas oriundas do clube da luta mental de Jack (Edward Norton) atingem, em cheio, todos aqueles que, de algum modo, não conseguem acompanhar o afã de consumo orquestrado pelos EUA, visto que:

Segundo a Bíblia, Deus é o criador e dono do Mundo. O impériosede do Papai Noel de mercado (os EUA) também acha que é o dono do Mundo e declara guerra contra todos os que sejam contrários. Papai Noel é o deus do consumo e é a atualização do deus mitológico da guerra - e mora na sede do império (a América do Norte), e não na Lapônia, como se pensava. Pela lógica, os EUA são o Olimpo. Marte - ou Papai Noel, como queira - é imortal, porque é filho de Deus, e George W. Bush é o deus-pai todo poderoso encarnado desejando o mundo para si. Completando a santa trindade, 0 povo, que espera ansiosamente para ir para o céu (PESSOA, 2001, p. 01).

A dissimulação norte-americana fez parecer à luz da opinião pública internacional, que Osama e Sadam e seus asseclas eram também nossos 
inimigos mundiais, que todos éramos, enfim, responsáveis por suas capturas e morte. Entretanto, acreditamos que não seja bem assim, em sentido estrito, mas que talvez isso possa dar-se sim, em sentido lato. Mas como é isso? Como pode ser e não ser responsabilidade nossa isso tudo?

\section{A FELICIDADE}

Sigmund Freud, em sua célebre obra O Mal-Estar na Civilização, vislumbra certa aversão em tecer críticas à sociedade norte-americana. Esta conduta, embora eivada de retórica, fica bem aparente, nestes termos: "Evitarei, porém, a tentação de ingressar numa crítica da civilização americana; não desejo dar a impressão de que eu mesmo estou empregando métodos americanos" (FREUD, 2002, p. 73).

No entanto, é justamente negando-se a criticar pontualmente os EUA, que, na mesma obra, Freud consegue um efeito contrário ou complementar ao que dissera (daí, então, se confirma o viés retórico de sua fala), construindo um texto bastante convincente - lançando uma crítica praticamente explícita aos rumos da humanidade -, quando faz referências à beleza do mundo primitivo do qual o homem descende:

O homem civilizado trocou uma parcela de suas possibilidades de felicidade por uma parcela de segurança. Não devemos esquecer, contudo, que na família primeva apenas o chefe desfrutava da liberdade instintiva; o resto vivia em opressão servil. [...] Quando, com toda justiça, consideramos falho o presente estado de nossa civilização, por atender de forma tão inadequada às nossas exigências de um plano de vida que nos torne felizes, e por permitir a existência de tanto sofrimento, que provavelmente poderia ser evitado; [...] (FREUD, 2002, p. 72).

Parece-nos, num primeiro momento, que Freud deseja realmente que a humanidade seja feliz, e, para alcançar essa plenitude, ficamos até tentados a entender que o autor desejasse incutir na cabeça do leitor a ideia de que a humanidade precisa romper com seus laços ancestrais de tribalidade e de submissão e inverter o curso histórico do rio sociocultural dentro do qual navega a qualquer custo. 
Quem lê essa passagem, ao pé da letra - um terrorista ou um fundamentalista, por exemplo -, pode apressar-se e sair por aí matando pessoas, derrubando prédios, arrancando a roupa no meio da rua etc. Tudo isso em nome de uma pretensa ruptura com o status quo ou de uma exteriorização de uma euforia reprimida, contida que estava pela força de coerção de nossas organizações sociais.

Vejamos o caso real emblemático de descompressão repentina, desencadeado por um acadêmico. Quando um jovem estudante de medicina, Mateus da Costa Meira, em 1999, num shopping center da cidade de São Paulo, em 1999, assistiu a uma sessão do filme Clube da Luta e, logo depois, saiu atirando e matando pessoas com uma metralhadora, o que ele fez? Entendeu o texto pictórico-verbal ao pé da letra e praticou uma insanidade seu "leão sociocultural saiu da jaula psíquica" dentro da qual nossa civilização o havia enjaulado. Por isso, isto é, devido a conteúdos relacionados ao psiquismo humano, é que, desde as imagens iniciais, o diretor do filme já nos dá a entender que essa temática seria mais bem abordada mediante à exploração do ambiente psicológico do homem e os limites de sua finíssima camada civilizatória.

A semiótica cultural, sob este aspecto, nos permite abordar as imagens introdutórias do Clube da Luta, apondo-as num paradigma que nos sugere, no passeio aéreo da câmera dramática, uma percepção panorâmica, uma vista do alto, construindo para o expectador, um ponto de observação a partir do qual se pode melhor perceber uma cadeia de neurônios: a navegação a partir de um "dentro" do mar cerebral humano. Essa câmera dramática, dionisíaca, vai mostrando, enquanto isso, os caracteres com os nomes do elenco, sob o som frenético de uma música eletrônica estridente. Desse modo, o desconforto sonoro associado aos nomes dos integrantes do elenco, apontam para a ideia de imersão na mente conturbada do personagem Jack, fazendo-nos crer que aqueles dados são, metaforicamente, elementos recuperados de suas memórias. Tal condição pode se confirmar, na medida em que a câmera caminha em sentido de marcha a ré, para trás, num movimento que se encerra somente ao sair pela garganta de Jack, subir pelo cano do revólver que estava 
dentro de sua boca, a partir do que se esclarecem ao expectador as circunstâncias dos fatos que aqui expomos.

A crítica à sociedade de consumo, como já viemos aludindo, é voraz. O exército de macacos que o personagem Jack organiza, sob os auspícios da loucura idílica de seu surto, teria por objetivo destruir, danificar e violar tudo o que fosse símbolo do capitalismo e da beleza que por meio dele se pudesse comprar.

O que vale comentar a esse respeito, é que nem mesmo o diretor do filme, David Fincher, talvez considerasse 0 ato de seu personagem algo louvável. O que não quer dizer que ele, o diretor, seja a favor ou contra ao capitalismo e à sociedade de consumo - é apenas uma inferência nossa.

Assim, temos que seu protagonista rivaliza e põe em seus atos de vandalismo contra o capitalismo, ao menos três instâncias psíquicas freudianas. Notadamente, sabe-se que uma delas é mais racional e engajada à sociedade, é o centro de equilíbrio, no qual se encarnariam as funções psicológicas mais próximas da instância a que Freud denomina Ego: "descrevi os numerosos relacionamentos dependentes do ego, sua posição intermediária entre o mundo externo e o id e seus esforços para comprazer todos os seus senhores ao mesmo tempo" (FREUD, 1969, p. 189). Vale dizer que dessas três instâncias psíquicas, duas são vividas pelo personagem Jack (ele próprio, como "ego", e o seu amigo imaginário, Tyler Durden, como id). O superego será encarnado pela personagem feminina, Marla Singer, vivida por Helena Bonham Carter.

Logo, outra instância psíquica presente do filme de David Fincher é a do superego. Marla Singer surge em cena e passa a ser o contato de Jack (o ego) com a realidade objetiva. Ela, no entanto, é arredia, demonstra ter vontade própria, quase impulsiva e um tanto coativa em relação a Jack (ego). Freud salienta que o superego "exibe sua independência do ego consciente e suas relações íntimas com o id inconsciente" (FREUD, 1969, p. 69). E é exatamente assim que ela se comporta. Afronta o Ego (Jack), e tem um caso amoroso com Tyler Durden (vivido por Brad Pitt, e que também encarna o papel mental de id). 
Daí, então, desembocamos na terceira instância psíquica freudiana, e que fecha a semântica psíquica do Clube da Luta a qual nos propusemos a apresentar neste texto. Portanto, o id ou Tyler Durden se torna a materialização do impulso idílico de Jack. Id é o inconsciente reprimido de Jack (o ego). É através da performance do idílico Tyler Durden, que o egônico Jackse realiza e busca auto-afirmação. No entanto, "O material reprimido luta contra esse destino. Cria para si próprio, ao longo de caminhos sobre os quais o ego tem poder, uma representação substitutiva (que impõe ao ego mediante uma conciliação) - o sintoma" (FREUD, 1969, p. 190).

O sintoma manifestado por Jack, nos moldes freudianos descritos, aflora sob a forma de uma rebelião contra a sociedade de consumo. O consumismo que o aflige age em seu soma por intermédio da posse que seus objetos materiais passam a ter sobre sua vida (tome cuidado com as coisas que você possui, por que, em algum momento, elas passarão a possuir você).

No início do filme Jack é um consumidor formatado, comportado e afeito a todo tipo de apelo publicitário destinado às compras. Com o passar do tempo, o que se percebe é que ele atinge um estágio de saturação mental dentro da cadeia de desejo pelo consumo (que, para ele, o ego, se apresenta sob a forma de opressão exercida pelo meio externo, a realidade).

A partir desse momento, é que a "luta" se inicia. O clube da luta (que no filme começa na rua e nos porões de um bar e se estende para as ruas das cidades) é também a alegoria da batalha psíquica que o cérebro trava com suas instâncias para tentar manter-se íntegro:

O ego descobre sua unidade ameaçada e prejudicada por esse intruso, e continua a lutar contra o sintoma, tal como desviou o impulso instintual original. Tudo isso produz o quadro de uma neurose. O ego entrou em conflito com o id, a serviço do superego e da realidade, e esse é o estado de coisas em toda neurose de transferência (FREUD, 1969, p. 190). [...] As neuroses correspondem a um conflito entre o ego e o superego, e as psicoses, a um conflito entre o ego e o mundo externo (FREUD, 1969, p. 192).

Lançando um olhar nostálgico em direção aos movimentos undergrounds dos anos sessenta, vemos que eles também espelharam um pouco dessa rebeldia com relação aos padrões da civilização. Mas, o que é 
relevante notar é que essa atitude revolucionária não lhes é exclusividade, visto que é inata no homem, e essa insurgência é bastante forte nele quando acredita ser por meio dela que se materializará o meio pelo qual se conseguirá a felicidade ou a libertação daquilo que acredita o estar oprimindo.

Ele, o homem, como emblema social da personalidade egônica idealizada da humanidade, deseja por ela a felicidade, a liberdade, e tende a destruir aquilo que aparentemente se ofereça como um obstáculo à consecução ou livre execução desses seus propósitos. Mesmo que a barreira se apresente sob as formas representativas da sociedade como torres comerciais, bandeiras nacionais ou dos pilares sobre os quais os civita (os Estados nacionais) se sustentem: a moral, a família, a dignidade, a justiça etc:

O superego, contudo, comporta-se como se o ego fosse
responsável por eles e demonstra, ao mesmo tempo, pela
seriedade com que pune essas intenções destrutivas, que elas
não são meras aparências evocadas pela regressão, mas uma
substituição real do amor pelo ódio. Impotente em ambas as
direções, o ego se defende em vão, tanto das instigações do id
assassino quanto das censuras da consciência punitiva (FREUD,
1969, p. 70).

É assim, portanto, que para o terrorista Osama, segundo esta leitura comportamental pautada na semiótica cultural, que o poderio econômico dos Estados Unidos poderia estar representando, de um lado, o maior grau possível de ameaça à sua felicidade ou liberdade e, de outro lado, encarnando o rival ideal que a seus olhos constituiria o par perfeito para compor a velha dualidade simbólica na luta entre o bem e o mal.

De qualquer maneira, seja afrontando a consecução plena da liberdade ou da felicidade, seja oprimindo o restante do mundo com dinheiro e armas, fato é que os Estados Unidos, hoje, são o estandarte da modernidade cobiçada por qualquer nação do mundo que queira ser considerada moderna, próspera, evoluída. Essa condição de referencial sócio-político e cultural, mesmo sob a vigência de uma lastimável pandemia de COVID-19, talvez ainda seja o objetovalor que mais afete a autoestima de certos líderes nacionais espalhados pelo mundo, e que também provoque de forma negativa os humores fundamentalistas de plantão nos orientes próximos, médios e distantes. 
Esse repudio, portanto, que parte, por certos motivos, dos governos nacionais, e por outros motivos, de fundamentalistas religiosos ou dos radicalismos políticos, abocam num mesmo conjunto de manifestações que dizem respeito a todo ser humano: o terrorismo, os embargos econômicos unilaterais, as guerras, os genocídios, os desvios de recursos, as fake news que manipulam os mercados financeiros e diariamente dão à luz a novos contingentes de miseráveis.

Num filme como o de David Fincher, podemos ter a representação fictícia de uma assustadora realidade. No entanto, o paradoxo é que ela, se considerada sob o ponto de vista da compreensão psíquica dos movimentos que a engendram, é muito mais comum e provável do que nossa razão amedrontada tenta sublimar:

Grande parte das lutas da humanidade centralizam-se em torno
da tarefa única de encontrar uma acomodação conveniente -
isto é, uma acomodação que traga felicidade - entre essa
reivindicação do indivíduo e as reivindicações culturais do grupo,
e um dos problemas que incide sobre o destino da humanidade
é o de saber se tal acomodação pode ser alcançada por meio de
alguma forma específica de civilização ou se esse conflito é
irreconciliável (FREUD 2002, p. 50).

Nesse sentido, entendemos que essa vertente de repudio, manifesta essencialmente via terrorismo, enquadra a antinomia Estados Unidos $\boldsymbol{x}$ Osama/Sadam no bojo de uma esfera de compreensão do problema de nossa crise civilizatória em sentido estrito. É também um problema quase pessoal, que envolve a desavença de um homem ou grupo de homens (o governo dos Estados Unidos e seu povo) em relação a outro homem ou grupo de homens (Osama/Sadam/Estado Islâmico/Rússia/China e seus povos).

Sob o ponto de vista ideológico, é uma demanda beligerante de locais múltiplos, e que, por isso, exigem uma solução global e ampla. O que quer dizer que não se justifica a omissão da comunidade internacional como entidade interventora e mediadora, uma vez que é grande a possibilidade de conflitos aparentemente restritos a setores econômicos ou sanitários se estenderem, devido aos embricamentos sociais e, principalmente políticos, que estão em jogo nesses litígios. 


\section{A CIVILIZAÇÃO E AS NOSSAS CONCLUSÕES}

Recuperando mais itens do pensamento de Freud, agora em outra de suas obras, a intitulada Totem e Tabu: a partir dela é que podemos melhor compreender o que, coletivamente, torna a civilização moderna uma doença autoimune, isto é, o terrorismo, a pandemia e seus correlatos fazem com que a civilização se torne alvo de si mesma.

O totem, segundo Freud, é uma espécie de ancestral comum que a sociedade primitiva elege para representá-la. Pode ser que esse ancestral seja um animal, planta, ou fenômeno da natureza. Esse se converte em símbolo de identidade coletiva e passa a ser o centro de energia do grupo social - o onfalus. É para ali, para o centro onfalógico, é que todos os esforços convergem.

Atualmente, transpondo essa simbologia do ancestral remoto para o recente mediato, verificamos que esse centro energético está deslocado e erigido sob a forma de igrejas, supermercados, shoppings. Não há cidadezinha que não tenha a sua igreja, seja uma catedral frondosa ou uma capela modesta. Não há grande cidade que não tenha ou queira ter o seu shopping center - ao menos, antes dos eventos da pandemia de COVID-19, era assim.

Desse modo, vê-se que, valendo-se quer de uma figura animal, de uma montanha ou de um tronco de árvore, seja ainda de uma igreja, de torres e arranha-céus ou de um shopping, todas as sociedades erigem seus totens.

Algumas tribos indígenas nomeavam esse centro onfalógico (centro de energia sociocultural) de "baíto". É no baíto, ou na "Casa dos Homens", que eram tomadas as principais decisões do grupo social. Para Freud, a ancestralidade e recorrência do totemismo, se explica muito pelo fato de que na sociedade civilizada, quando a comparamos com os grupamentos sociais primitivos, a tecnologia pode ter avançado vários estágios, porém, os homens, ainda continuam os mesmos, desde as cavernas, desde as bigas, até os dias atuais nas espaçonaves estelares.

Nos grupamentos primitivos, lembra o Freud, "o caráter totêmico é inerente, não apenas a algum animal ou entidade individual, mas a todos os 
indivíduos de uma determinada classe" - e o que complementa essa ideia diz respeito a muito de nosso modus vivendi moderno - "De tempos em tempos, celebram-se festivais em que os integrantes do clã representam ou imitam os movimentos de seu totem em danças cerimoniais" (FREUD, 1913/14, p. 20).

A festa dionisíaca capitalista convida todo mundo a entrar. Parece possível a todo e qualquer ser humano, ser e comportar-se como o melhor de sua espécie, ter tudo o que é bom nesse cenário é valorizado. Mas, no entanto, nas letras miúdas do contrato social capitalista, só participa da festa quem pode pagar por ela.

Os desejos são estimulados indistintamente. A propaganda é destinada a quem quiser vê-la, mas, o acesso ao produto veiculado por ela com o aspecto mais desejável mundo, apenas alguns poderão ter. O resultado imediato emerge na condição de frustração, violência e rejeição às pessoas, aos hábitos.

Esse desejo frustrado irrompe violentamente, quando o ego agoniza diante da corrupção de sua sanidade, recalcada e confinada à guarda nos porões do id. É assim que a luta, no Clube da Luta, começa.

No filme de David Fincher, o clube dessa luta psicossocial começa num bar - ele é alegoricamente o porão, o submundo da sociedade. A revolta contra os desejos estimulados pela propaganda de massa e não satisfeitos pelos salários mal pagos emergem agressivamente - e os personagens dizem isso aos telespectadores.

No terceiro mundo empobrecido, na periferia das cidades ou nos países em desenvolvimento - ou no imenso contingente de financeiramente vulneráveis ao COVID-19 -, os que não têm acesso ao que o mundo do consumo mais rico pode desfrutar, o fracasso vem à tona sob a forma de vandalismos, sequestros, furtos, roubos, uso de drogas. No universo psíquico, então, isso aparece sob a égide da frustração e desencadeia uma batalha titânica entre o superego, o ego e o id.

Tentando atender ao desejo de id (Tyler Durden) e superego (Marla Singer), o ego (Jack) sucumbe, se mata, se esfacela.

Reestabelece a ordem da normalidade. Remete o id ao seu lugar de origem (Jack "mata" a tiros, a imagem mental de Tyler Durden) - as 
profundezas de sua inconsciência paradoxalmente se restauram pelo caos desmoronador da civlização.

No final do filme, harmonizam-se ego e superego, e, de mãos dadas, Marla Singer (superego) e Jack (ego), reificam o mito cristão da criação por meio do casal original adâmico e contemplam a destruição do mundo capitalista pela paisagem vista da janela de seu "apartamento" localizado no sótão de nossa ignorância.

\section{REFERÊNCIAS}

FREUD, Sigmund. Totem e Tabu. Rio de Janeiro: Imago, 1913/14.

Imago, 1969. . O Ego e o ld - uma neurose demoníaca. Rio de Janeiro: . O Mal-Estar na Civilização. Rio de Janeiro: Imago, 2002.

PESSOA, Marcelo. Supermercado Não é Lugar de Felicidade. Jornal Folha de Rio Preto, 05/12/2001.

\section{ADICIONAIS}

Link para o filme no Youtube:

https://www.youtube.com/watch?v=bX9r6v69pgU\&t=4649s 